Research article

\title{
Inhibiting integration and strengthening inequality? The effects of UK policy making on refugees and asylum seekers in Wales
}

\author{
Samuel Parker* \\ School of Social Sciences, Birmingham City University
}

\begin{abstract}
In 2001, following the Immigration and Asylum Act 1999, four towns and cities in Wales became asylum dispersal locations. Whilst immigration and asylum remain matters reserved to the Westminster government, the Welsh Government has devolved responsibility in social policy areas that may impact upon refugee integration. This article highlights how successive Westminster governments have introduced immigration and asylum legislation creating a 'hostile environment' for asylum seekers. Such policies have restricted the civil and social rights of asylum seekers whilst simultaneously the Westminster government has focused upon policies for the integration of those granted refugee status only. This article reports on the findings from interviews conducted with 19 refugees and asylum seekers living in Wales, where in contrast to Westminster, the Welsh Government see integration as a process beginning on day one of arrival in Wales. It demonstrates how policies introduced by the Westminster government have led to restrictions on the day-to-day lives of forced migrants in Wales and their ability to integrate. It argues that in a system of multi-level governance, the Welsh Government's vision of being a 'Nation of Sanctuary' and for integration from day one remains difficult to achieve when immigration and asylum remain matters reserved to Westminster.
\end{abstract}

Keywords: Refugees, asylum seekers, integration, inclusion, Wales

\section{Introduction}

In January 2019 the Welsh Government published a new refugee and asylum seeker plan with the stated aim for Wales to be "a true Nation of Sanctuary for refugees and asylum seekers' (Welsh Government, 2019: 3). Within this plan they acknowledge that, despite having devolved responsibility for many of the social policy areas relevant to refugee and asylum seeker integration (such as education, health, housing and social services), the ability to fully resolve issues faced by such communities in Wales and realise its vision would rely on policy change from the Westminster government. This article therefore explores the impact of multi-level governance structures in the UK for the integration of refugees and asylum seekers within the devolved, Welsh context. It

Copyright: (C) 2021, Author(s). This is an open access article distributed under the terms of the Creative Commons Attribution 4.0 License, which permits unrestricted use, distribution, and reproduction in any medium, provided the original author and source are credited. 
p. 73. Inhibiting integration and strengthening inequality? The effects of UK policy making on refugees and asylum seekers in Wales

builds on work by Mulvey $(2015 ; 2017)$ that explored the effect of UK policy making on refugee integration in Scotland, extending this to consider integration in Wales which, whilst sharing similarities with Scotland, has recently gone further in its commitment to refugees and asylum seekers through its desire to be the first 'Nation of Sanctuary'. In doing so, the questions the present article seeks to address are: does UK Government immigration and asylum policy inhibit refugee and asylum seeker integration in Wales and is it possible for the Welsh Government to mitigate adverse effects through their devolved social policy making powers?

In this article, I use the term 'refugee' to refer to those who have been recognised by a national government as meeting the requirements of the 1951 United Nations Convention relating to the Status of Refugees. I use the term 'asylum seeker' to refer to those who have 'crossed an international border in search of protection, but whose claim for refugee status has not yet been decided' (Castles et al. 2014: 222). This distinction is important in the UK and devolved context in relation to debates about when 'integration' should begin. It represents an area of policy in which the UK government approach has increasingly diverged from that of the devolved nations. The UK government see this as a process that can only begin once refugee status is awarded (Home Office, 2000) whilst the Welsh Government's (2019) more inclusive approach sees 'integration' (or 'inclusion') beginning on day one of arrival in Wales.

Following publication of its first refugee integration strategy (Full and Equal Citizens, 2000) the UK Home Office commissioned academics to undertake research into integration and develop a framework for integration. The definition of integration in Ager and Strang's (2004) 'Indicators of Integration Framework' is therefore used in this article due to the influence that it has had on subsequent UK and devolved government integration strategies. In this framework they state that:

"An individual or group is integrated within a society when they: achieve public outcomes within employment, housing, education, health etc. which are equivalent to those achieved within the wider host communities; are socially connected with members of a (national, ethnic, cultural, religious or other) community with which they identify, with members of other communities and with relevant services and functions of the state; and have sufficient linguistic competence and cultural knowledge, and a sufficient sense of security and stability, to confidently engage in that society in a manner consistent with shared notions of nationhood and citizenship" (Ager and Strang, 2004: 5-6).

Despite this definition, the literature on integration suggests that it is a complex, contested and multidimensional concept (Phillimore, 2011); likewise exactly what an 'integrated community' might actually look like is also heavily contested. Indeed, it is often assumed that 'integrated communities' are a 'public good' (Mulvey, 2015) which may explain the frequent use of the term within policy, practice and academia. Stewart and Mulvey (2014) suggest that previous research differentiates between structural integration (participation in society's main institutions) and acculturation (changes in identity and culture). Phillimore (2012), in reviewing literature on what might be classed as successful integration found that access to public services, developing social capital and seeing integration as a two-way, multi-dimensional, process were commonly reported. According to Phillimore (2011) such arguments developed to counter the school of thought that saw integration as a linear process which all migrants must pass en route to assimilation (e.g. Favell, 1998). Castles et al. (2014) highlight, however, that many policy agendas and lay conceptions of integration continue to treat integration in this "one-way", linear fashion whereas researchers and experts in the area of refugee integration have argued for a "two-way process". 
p. 74. Inhibiting integration and strengthening inequality? The effects of UK policy making on refugees and asylum seekers in Wales

The article begins with an overview of the relationship between UK immigration and integration policies where I argue that despite integration of refugees being a stated Westminster government aim, conflict with 'hostile' immigration policies aimed at deterring asylum seekers makes this a dilemmatic relationship. I then proceed to discuss the Welsh context and argue that the integration of refugees and asylum seekers takes place predominantly within social policies that are devolved to the Welsh Government. As such, I will argue that there is an on-going tension between the Welsh Government's stated aims of inclusivity and integration, and the 'hostile environment' approach taken to immigration policy by the Westminster government. There is a lacuna in academic research focusing on refugees and asylum seekers in Wales, which this article seeks to address (cf. Crawley and Crimes, 2009; Crawley, 2013). The main part of this article reports findings from interviews undertaken with refugees and asylum seekers living in Wales and I show how this dilemma between integration and restriction is evident in the talk of participants.

\section{UK immigration and asylum policy}

The UK's first immigration legislation (The Aliens Act 1905) was introduced with the aim of restricting Jewish immigration. Even in this period of colonialism, migration was not new. However, it was not until the end of the Second World War and the beginnings of decolonisation that the concept of British citizenship was first defined in the 1948 British Nationality Act. This Act gave people from colonies and former colonies British nationality rights. Goodfellow (2019) suggests that the original aim of this Act, which appeared to be an open door policy, was to make it easier for those from 'white dominion' countries to come to the UK and as such, people of colour were not welcome. This idea was further strengthened through the concept of 'patriality' in the Immigration Act 1971 which made it more difficult for non-white commonwealth citizens to come to the UK. At the same time as increasingly restrictive immigration acts were introduced, the Race Relations Acts of 1965, 1968 and 1976 were also passed, with the aim of giving those who had migrated greater protection from discrimination.

Whilst the model entrenched between 1948 and 1976 remains dominant, further changes to UK immigration policy were introduced under the leadership of Tony Blair in response to the increasing numbers of asylum seekers entering the UK to claim refugee status in the 1990s and early 2000s. New Labour's approach to immigration focused on securing the 'economic benefits' of migration, making it easier for those deemed 'desirable' to enter and work in the UK through what they termed 'managed migration' (Goodfellow, 2019). By contrast, asylum seekers were seen by New Labour as economically 'undesirable' and resulted in a raft of legislation being introduced which has been described as creating a 'hostile environment' (Bloch and Schuster, 2005; Sales, 2007) for asylum seekers (and by implication those recognised as refugees). This 'hostile environment' is one in which destitution, detention, deportation and dispersal are used as a means of both discouraging asylum seekers from entering the UK and encouraging refused asylum seekers to leave the UK.

In the context of the current article the introduction of compulsory 'no-choice' dispersal away from London and the southeast for those who required housing support, is perhaps the most significant of these 'hostile' policies. Following introduction of the 1999 Immigration and Asylum Act, and the creation of the National Asylum Support Service (NASS), four towns and cities in Wales (Cardiff, Newport, Swansea and Wrexham) became dispersal locations for the first time, marking the first significant arrivals of asylum seekers in Wales' recent history (Crawley, 2013). The Act also introduced a new system of welfare support for asylum seekers, removing their access to mainstream 
p. 75. Inhibiting integration and strengthening inequality? The effects of UK policy making on refugees and asylum seekers in Wales

welfare benefits and prohibiting them from working whilst waiting for a decision on their claim for protection, leading scholars to claim that this amounts to a deliberate policy of enforced destitution for asylum seekers (Allsopp et al., 2014).

At the same time as introducing 'hostile' policies for asylum seekers, New Labour also attempted to 'integrate' those awarded refugee status and introduced three refugee integration strategies during their time in government. Thus, a government who aimed to deter asylum seekers from entering the UK in the first place also presented themselves as wanting to 'integrate' those deemed to have earned the right to be awarded refugee status. In their first refugee integration strategy, Full and Equal Citizens (2000) and its follow-up Integration Matters (2005), it is clearly stated that 'integration' is a process that is for refugees only, as it is only they who have the ability to plan for a long-term future in the UK. However, the strategies do acknowledge that 'integration experiences' may occur before the awarding of refugee status. This highlights the dilemma faced by the UK government in differentiating between refugees and asylum seekers and permitting 'integration' to begin only once refugee status has been awarded. In the next section I discuss how the approach taken by the Welsh Government avoids such a dilemma but I argue that a more significant dilemma is apparent for the Welsh Government between devolved (social) policies and 'reserved' immigration and asylum policy.

\section{Refugees and asylum seekers in Wales and Welsh Government refugee 'inclusion' policy}

In Wales, constitutional changes began the process of devolution and the creation of the National Assembly for Wales, in 1999. Chaney (2011: 69) describes such changes as a 'move to quasi-federalism' in the UK with the National Assembly gaining legislative powers in social policy areas such as education, housing, health and social services. Giudici (2014) argues that an inclusive rhetoric has been a feature of Welsh political discourse since the early days of the National Assembly, suggesting that such "postdevolution inclusiveness can be seen as functioning as a national boundary between Wales and England, the former self proclaiming more 'welcoming' than the latter' (Giudici, 2014: 1,412). Chaney (2011) has further highlighted that a mainstreaming approach to equalities has been adopted by the Welsh Government, embedding equalities legislation into all of its policies, however, specific strategies relating to refugee and asylum seeker inclusion have also been published by the Welsh Government.

Since the beginning of dispersal to Wales in 2001, the percentage of UK asylum applicants dispersed to Wales has increased, from 3.9 per cent in 2004 to 6.2 per cent in 2020 (Home Office, 2021). At the end of 2020 there were 2,829 section 95 supported asylum seekers accommodated principally in Wales' four dispersal locations (50.1 per cent in Cardiff, 29.4 per cent in Swansea, 15.6 per cent in Newport and 4.3 per cent in Wrexham). However, this figure does not include those receiving Section 98 support (initial support before application for Section 95 support), nor those appealing a Home Office decision not to grant refugee status, who may either be destitute or receiving Section 4 support, meaning that the actual total number of asylum seekers living in Wales may be considerably higher than 2,829 . Home Office (2020) data shows that in 2020 there were individuals applying for asylum, supported under Section 95, from 84 different countries, which contrasts sharply with Robinson's (1999) earlier findings which identified only 15 different nationality groups.

Reporting an accurate number of refugees who may be living in Wales is similarly difficult because, once refugee status has been granted (by the UK Home Office), 
p. 76. Inhibiting integration and strengthening inequality? The effects of UK policy making on refugees and asylum seekers in Wales

individuals have the option to move away from the area and, secondly, because the decennial census does not specifically record if respondents are refugees. Robinson (1999) estimated that there might be between 3,500 and 3,600 refugees living in Wales, however some 14 years later, Crawley (2013) suggested that the figure was now between 6,000 and 10,000. Adding to this, in recent years, all Local Authorities in Wales have taken part in the UK government's Syrian Vulnerable Persons Resettlement Scheme (SVPRS), meaning that refugees now live across Wales, although the numbers in most parts of Wales remain very low.

Despite such recent increases in refugee and asylum seeker numbers in Wales, little research has been undertaken which explores the experiences of these groups. The largest study into refugee inclusion in Wales was conducted by Crawley and Crimes (2009), commissioned by the Welsh Assembly Government. This study looked at a number of the 'means and markers' identified by Ager and Strang (2004) within the Welsh context. However, only those who had received a grant of refugee status were eligible to participate in the study. Analysing responses to 123 questionnaires Crawley and Crimes (2009) found that most of the respondents were living in rented accommodation and very few owned their own homes. In terms of education, 75 per cent of respondents had arrived in the UK with at least secondary education and since living in Wales a third of respondents had completed an English language course. Despite over two thirds of respondents having been employed in their home countries, only one third had found employment in Wales. Whilst this study did not seek the views of asylum seekers, the findings nevertheless highlight the importance of the social policy areas that are the devolved responsibility of the Welsh Government to the longer-term integration experiences of refugees. However, it is perhaps surprising that this report did not seek to engage asylum seekers in the research given the stated aim of inclusion from day one of arrival in Wales.

Since the publication of New Labour's third and final refugee integration strategy in 2009 , the devolved governments of Wales and Scotland have continued to publish and revise their own refugee integration strategies. However, the Conservative and coalition governments at Westminster have not issued their own integration strategy specifically for refugees. Instead the policy focus has been more broadly on people contributing at a neighbourhood level with voluntary and private sector organisations leading such action rather than central government (CLG, 2012). Following the 2016 Casey Review, which criticised the lack of focus on integration, the Ministry of Housing, Communities and Local Government (MHCLG) published an Integrated Communities Strategy Green Paper in 2018 which again used definitions of integration seen in earlier refugee integration strategies but was broader in focus and not specifically targeted at refugees. As such, it can be argued that in recent years, UK government refugee integration policy has increasingly diverged from that of the devolved nations.

\section{Methods}

The data in this article come from a larger research project, carried out between 2015 and 2017, looking at the integration experiences of forced migrants in Wales, UK. The data consist of semi-structured interviews with 19 asylum seekers and refugees who had been living in Wales between one month and twelve years at the time of interview. 12 participants lived in Cardiff, five in Swansea and two in Newport. Eleven of the participants were male and eight were female. They were from thirteen different countries of origin (Sudan, Iran, Syria, Eritrea, Ethiopia, Sierra Leone, Pakistan, Kenya, Chechnya, Nigeria, Iraq, Egypt and Uganda). Four participants were asylum seekers who had made an initial application for protection to the UK Government and seven were 
p. 77. Inhibiting integration and strengthening inequality? The effects of UK policy making on refugees and asylum seekers in Wales

asylum seekers who were appealing a decision to refuse their claim by the UK Government. Seven participants had been recognised as refugees and granted five years leave to remain in the UK and one participant had been granted British Citizenship.

An interview guide was constructed using the 10 domains identified in Ager and Strang's (2004) 'Indicators of Integration framework', because of the influence this framework has had in developing UK and devolved government refugee integration strategies. Therefore there were questions on topics such as health, housing, education, work, safety and social relationships. Full consent was obtained from each participant before the interview began. Interviews lasted for between 25 and 70 minutes and were subsequently transcribed. In the extracts that follow, pseudonyms are used for each of the participants in order to protect their identities.

Each of the transcripts were analysed using a deductive (theoretical) form of thematic analysis (Braun \& Clarke 2006) drawing on the domains of the 'Indicators of Integration Framework'. Each of the transcripts was initially coded based on these ten domains and then broader themes relating to the experiences of participants within these domains were identified. One of the themes identified was restriction, which is the focus of the remainder of this article. The extracts that are reported in the findings section were selected as being those that best represent the theme of restriction.

There are several limitations of the data presented here that should be noted. Firstly, none of the participants lived in the Wrexham dispersal area. However, as discussed above, the primary asylum dispersal locations in Wales are located in the south of the country, with only very small numbers housed in Wrexham (4.3 per cent). Secondly, participants were recruited with the help of third sector organisations which may mean that the data is not fully representative of all refugees and asylum seekers in Wales given that they will not all be engaged with support organisations. Finally, interviews were conducted in the medium of English and thus the experience of those with less developed English skills are not represented in the sections which follow.

\section{Findings}

In the introduction to this paper I highlighted the ways in which differing forms of multilevel governance have resulted in policy divergence between the UK and devolved governments in their approach to the integration of refugees and asylum seekers. In this section, I begin by reporting on the restrictions faced by participants from the UK government's asylum policies. I suggest that although the Welsh Government have in many ways attempted to mitigate the effects of the UK government's hostile environment approach with its own refugee integration strategies, it remains the most prominent form of restriction described by participants in this research. Then, in the section which follows, I show how restriction was also a theme within the social policy areas for which the Welsh Government have devolved responsibility.

\section{Restrictions of the UK asylum system}

The 'Foundation' level of the 'Indicators of Integration Framework' (2004) includes the domain of 'rights and citizenship' and relates to the degree to which refugees are able to engage fully in society, the rights they have and what is expected of them. In their Nation of Sanctuary Plan (2019), the Welsh Government link their intended actions to their Well-Being of Future Generations (Wales) Act 2015, which includes a focus on those in Wales being 'prosperous and secure'. However, asylum seekers receive only $£ 39.63$ per week and Allsopp et al. (2014) have shown that these rates, set by the UK government, are not sufficient for meeting everyday essentials such as food, clothes and 
p. 78. Inhibiting integration and strengthening inequality? The effects of UK policy making on refugees and asylum seekers in Wales

transport and also criticise the UK government for keeping rates of support stagnant in recent years, despite increases in the rates of mainstream welfare benefits. Asylum support was discussed by many of the participants during the interviews and, in particular, by those awaiting a decision from the UK government on their asylum claim or who were appealing refusal of their claim. Extract 1 below is from an interview with Mustafa, a refused asylum seeker receiving section 4 support, in which he describes being unable to do anything because of restrictions he faced as a result of receiving less than $£ 40$ per week. Whilst the UK Government state that the rate of asylum support should cover food and essential living costs such as clothes and toiletries (Gov.uk, 2018), in this extract Mustafa directly contradicts this by suggesting that it is "just for food" and that he "can't buy new clothes".

\section{Extract 1}

"It's just it's just for food [..] if you if you are a smoker you have to stop smoke you can't do anything with thirty five pound a week you know [..] I think I can't move from here to anywhere I want you know? You can't buy new clothes if you don't have someone to support you some money so yeah if you are not working you don't know anything just with this money you are yeah it's not enough." (Mustafa, refused asylum seeker, 12 months in Wales)

Mustafa raises a number of points that impact on his ability to integrate and participate in society as a result of having to rely on asylum support: the ability to move freely and being unable to develop knowledge that comes from being in employment. In the introduction to this article, I described the ways in which the UK Government have faced a dilemma between the deterrence of asylum seekers and the integration of refugees. Such a dilemma fails to consider the intimate linking of the categories 'asylum seeker' and 'refugee' in that many of the refugees in Wales, and the UK, will have been asylum seekers prior to receiving refugee status. As such, this dilemma between Mustafa's current status as an asylum seeker and his ambitions for longer-term integration (working and moving freely) are apparent here, representing a potential problem for the Welsh Government's view of integration beginning on day one of arrival in Wales.

In Extract 2, below, Bhaija, offers a similar account to Mustafa. Bhaija lists a number of ways in which she is restricted by the current asylum system, including being unable to buy a new dress or go to the hairdressers.

\section{Extract 2}

"Yeah amount of money because it's like people can't survive on benefits they need to do job for their survival and if you survive on $£ 36$ I don't know how can a person survive on $£ 36$ a normal British person? It's really worse because you need money for everything and even for going to salon or going to buy a new dress or anything you need money or even for travel you need money or food." (Bhaija, refused asylum seeker, 12 months in Wales)

What is interesting about this extract is the way in which Bhaija explicitly questions how a "British person" could survive on the asylum support rate, particularly if integration is conceptualised based on equality of rights. This supports Cholewinski's (1998) claim that 'enforced destitution' is a key tenet of the UK government's 'hostile environment' and raises the question of what approach the Welsh Government could take to mitigate these effects if it is to achieve its aim of becoming a 'Nation of Sanctuary'. Indeed, in their new Plan, one of the aims is to 'promote financial inclusion for refugees and asylum seekers to avoid destitution, reduce or mitigate the impacts of poverty and improve living 
p. 79. Inhibiting integration and strengthening inequality? The effects of UK policy making on refugees and asylum seekers in Wales

conditions for those on low incomes' (2019: 13). However, it is not clear how, for asylum seekers, this is to be achieved, with only the 'Discretionary Access Fund' (requiring a National Insurance Number that asylum seekers do not have) suggested as the means of mitigating the impacts of poverty that result from the UK Government's 'hostile environment' approach. Extract 2 similarly suggests that for participants in this study 'sanctuary' is about much more than just 'safety' and that having the right to work and participate equally in society are also an important element of 'sanctuary'.

Other refused asylum seekers spoke of a more total restriction during their interviews. Ghirmay (Extract 3) had been living in Wales for over three years at the time of interview and spoke of being "like a moving dead" because of his status as an asylum seeker and his perceived lack of rights and inability to participate in society.

\section{Extract 3}

“...nothing gonna get changed unless you have got your visa you are- erm to be honest I am like a moving dead (.) I can't do nothing I can't do study I can't work I can't do anything(.) nothing and it's quite suffering and just it's getting my nerves and it's nerve wracking and it's (.) very bad." (Ghirmay, refused asylum seeker, 3 and a half years in Wales)

As with Extracts 1 and 2 the restriction described by Ghirmay comes from the asylum policy that is reserved to the Westminster government. At the same time, it also implies that the key to overcoming such restriction would be to receive refugee status ("got your visa"). This suggests that the UK government's approach of seeing integration as a process that can only begin once refugee status is awarded may be playing out here, despite the Welsh Government's vision for integration being one that begins on day one of arrival in Wales.

\section{Restrictions in Wales}

In the previous section I analysed accounts of restriction reported by asylum seekers in Wales in which the restriction they faced was attributed to the asylum policy of the Westminster government. I suggested that such restrictions were a major obstacle to achieving the Welsh Government's ambition of becoming a 'Nation of Sanctuary'. However, I also indicated that in the current Nation of Sanctuary plan the Welsh Government are attempting to mitigate such effects. Whilst I suggested that the restrictions described by participants were as a result of reserved UK asylum policy, within the interviews, participants also reported restrictions in areas of social policy which are devolved to the Welsh Government, which I discuss in this section.

In Wales, asylum seekers are, in theory, able to access English for Speakers of Other Languages (ESOL) classes from day one and the Welsh Government do have a current ESOL Policy for Wales (Chick and Hannagan-Lewis, 2019). This differs significantly from the UK government approach which, in England, means that asylum seekers are only able to access this provision if they have been waiting for more than 6 months for a decision on their asylum claim.

In Extract 4, Samir, who had been awarded refugee status shortly before the interview, describes the restrictions he faced in accessing English language provision when he arrived in Wales.

\section{Extract 4}

"I registered before entering college two months. When I went to the reception and asked her- them to register they told me there very-there lots of people before you 
p. 80. Inhibiting integration and strengthening inequality? The effects of UK policy making on refugees and asylum seekers in Wales

waiting two er two years. I can't and I tried and tried lots of times and finally I ask I asked to speak with the manager I explained my needs. I need I need to learn English and I asked in seriously so they put me in the college." (Samir, Refugee, 9 months in Wales).

In this extract, Samir reports being told that he would have to wait for 2 years in order to access ESOL provision. Crawley (2014) has suggested that demand for ESOL provision in Wales far outstrips supply, is insufficiently funded and that there are difficulties in recruiting and training ESOL tutors in some areas of Wales. The importance of learning English is stressed by Samir suggesting that he sees this as a key part of his integration. ESOL provision is identified by the Welsh Government as a priority in the Nation of Sanctuary plan (2019) and a number of measures are identified to tackle the issues that Samir describes. Principally this is to be achieved through the 'ReStart: Refugee Integration' project and the development of ESOL hubs in each of the four dispersal locations, to allow quicker assessment of students' needs and greater ESOL provision. As such, this is an example of the Welsh Government using its devolved powers to address one of the key themes of restriction found in the interviews for this study.

The new 'ReStart: Refugee Integration' project may also be well placed to address the restrictions reported by other participants, such as Hayat who said that "I tried in story classes but the problem is the children I can go anywhere they have crèche for the children but not always is available the crèche". This indicates that it is not just the availability of courses that impacts on the ability to attend formal education. Indeed, it suggests that it is the unavailability of suitable childcare that may restrict many refugee mothers from engaging in such integration activities. The Welsh Government do acknowledge such difficulties and aims to address these barriers to accessing education, such as childcare or transport arrangements, through the creation of a 'Barriers Fund' as part of the ReStart: Refugee Integration project.

The Welsh Government's Nation of Sanctuary plan (2019) also suggests that its 'Flying Start' programme is one of the ways in which barriers and restrictions can be mitigated. Although billed as their flagship early years programme, 'Flying Start' is only available to families in the most disadvantaged areas of Wales (as measured by the Welsh Index of Multiple Deprivation) and includes free childcare for two to three year olds, enhanced health visiting, parenting support and support for early language development. However, one of the participants specifically voiced her anger at being ineligible for this scheme due to her postcode, see Extract 5, below.

\section{Extract 5}

"So like if I want to go into college now even if they give me the admission I have to sit properly and think if probably the person who will help me that I have been helping before is still available to help me the way I gave the help to them when they are in need of it. So if the person is not available I don't have the money to pay for the childcare so I have to drop it that means I can't go to school and when she was like two and half years I struggled a lot to get her into nursery for the flying start but it's not just working because they said oh your postcode is not in the catchment area sorry she can't come in it was really devastating because then I was really really struggling" (Layla, refused asylum seeker, 4 years in Wales)

In this extract, Layla makes it clear that being eligible for 'Flying Start' would have made a positive difference to both her (in allowing access to college) and to her children (in getting out and doing things together). Thus, whilst there are positive attempts to mitigate the effects of UK asylum policy within the strategy, it may not help all those who seek sanctuary in Wales. 
p. 81. Inhibiting integration and strengthening inequality? The effects of UK policy making on refugees and asylum seekers in Wales

Whilst Education represents a key area of policy divergence between Westminster and the Welsh Government in terms of ESOL provision (Chick and Hannagan-Lewis, 2019), with the Welsh approach demonstrating the commitment to integration from day one of arrival in Wales, the Welsh Government have done little to make Higher Education available to those seeking asylum.

\section{Extract 6}

"Well what happened was because I was an asylum seeker at the time I applied for universities I had replies from every single university saying oh sorry you can't be offered this place because this specific course is not open for international students so they considered me as an international student with the international fees you know which is about twenty five thousand per year heh heh" (Aysha, refugee, 4 years in Wales)

Although UK Government policy does not prohibit asylum seekers from entering Higher Education, their classification as international students, whilst receiving less than $£ 40$ per week, means that they are effectively excluded due to the cost, as described by Aysha in Extract 6 . Following receipt of refugee status Aysha was able to receive student funding and was able to gain a university place through clearing. However, she was not able to attend any of her first choice universities (in Wales and near her family) and had to accept the offer of a place at a university in London that offered a January start. In their Nation of Sanctuary plan (2019) the Welsh Government only go as far as committing to explore the potential eligibility for asylum seekers to access student loan funding rather than making a policy change to allow asylum seekers to attend university as home students.

Perhaps, most problematic for the Welsh Government's vision of integration relates to employment and, in particular Home Office rules which prohibit asylum seekers from entering paid employment. In Extract 7, below, Awet describes how being unable to work has been a barrier to integration for him, both financially and in terms of making the social connections that Ager and Strang (2004) suggest are measures of successful integration.

\section{Extract 7}

"Yeah I see like a huge barriers it's like a mountain stopping me from doing that (integration) because when you don't do work or interact with like the general public you in turn have to develop like psychologically like you see yourself down or you lack in motivation to do participate or to do anything or like what's in it for me?" (Awet, refused asylum seeker, 3.5 years in Wales)

Awet's account emphasises the central role that the absence of work plays in his life and supports Ager and Strang's (2004) view that employment is both a means to and marker of integration. Whilst initiatives such as the ReStart: Refugee Integration project may help those with refugee status to enter employment, there is little in the plan which addresses the negative consequences of being unable to work whilst waiting for a decision on an asylum application, such as those described by Awet and others in this research.

\section{Discussion and conclusions}

The primary aim of this article was to consider whether UK Government asylum policies inhibit refugee and asylum seeker integration in Wales through applying the "Indicators 
p. 82. Inhibiting integration and strengthening inequality? The effects of UK policy making on refugees and asylum seekers in Wales

of Integration Framework' (Ager and Strang, 2004) to analysis of interviews with current refugees and asylum seekers in Wales. The findings of this study indicate a complex relationship between reserved immigration policy and devolved (Welsh) integration policies that play out in the day-to-day lives of refugees and asylum seekers in Wales. They also pose a challenge for the Welsh Government's vision for a 'Nation of Sanctuary' in which integration begins on day one of arrival in Wales. Indeed, as Mulvey (2015: 372) has argued 'policy with regard to refugees is not simply reserved or devolved. Instead there is a marbling of responsibilities in different areas and at different levels'. Whilst previous studies of integration in Wales (Crawley and Crimes, 2009) have focused on the experiences of those granted refugee status only, this study also considered the experiences of asylum seekers. It demonstrates that whilst asylum seeking participants in particular experienced barriers to integration as a result of the UK government's asylum policy, there were also areas of devolved responsibility that were highlighted as barriers to integration by asylum seeking and refugee participants.

Analysis of the interviews for this study revealed a strong theme of restriction, particularly from Section 4 supported asylum seekers, who described the rates of support as restricting their ability to integrate in Wales. The findings of this study not only support previous research findings (Refugee Action, 2013) but also question the UK government's claims that the level of support is sufficient to cover essential living costs. Although Ager and Strang's (2004) 'Indicators of Integration Framework' does not suggest an amount of financial support needed to enable integration, it is clear that many of the 'indicators' rely upon having the necessary resources to engage in integration activities, particularly at the 'Foundation' level of the framework. Ager and Strang (2004:5) also recognise the importance of achieving outcomes equivalent to members of the wider host community, but again it is difficult at present to see how this can be possible when asylum seekers receive less than half than those on mainstream benefits receive per week. However, as analysis of Extract 6 from Aysha demonstrates, the effects of hostile asylum policies can also continue to play a role once refugee status has been granted. This may be a case of what Mulvey (2015: 372) describes as a 'marbling of responsibilities' where the Welsh Government have devolved education powers but it is the asylum policy of the UK government which has caused Aysha to be restricted. As such, the evidence presented in this article does suggest that reserved asylum policy inhibits refugee and asylum seeker integration in Wales (particularly if integration is viewed as a process beginning on day one of arrival in Wales as an asylum seeker).

The secondary aim of this article was to consider whether it was possible for the Welsh Government to mitigate any adverse effects of UK asylum policy through their devolved social policy making powers. Indeed, the Welsh Government have claimed this to be an aim of their refugee inclusion strategies to date. However, the findings of this study indicate that this was not always evident in the interview data and that further work is required to achieve this aim. Key amongst this was the reporting of difficulties in accessing educational opportunities, an area devolved to the Welsh Government. Extract 4 from Samir suggested that it was the availability of English language courses that restricted his integration opportunities (a theme common across the interviews). However, other extracts demonstrate that for single asylum seeking women with children there are both financial and childcare barriers that restrict access to education. This highlights where the intersection between reserved asylum policy (financial support) and devolved social policies (access to education and provision of childcare in colleges) combined to exclude these participants from accessing learning opportunities that would aid their integration. Sales (2002: 467) argues that women are likely to disproportionately feel the impacts of the UK government's dispersal policy and are more likely as a result to be isolated from community and kin networks that could help them to develop a sense of belonging in the UK. As such, these findings indicate that the Welsh 
p. 83. Inhibiting integration and strengthening inequality? The effects of UK policy making on refugees and asylum seekers in Wales

government should give additional consideration to ensuring that the effects of any UK government asylum policy are mitigated for this particular group.

The findings of this article support the argument made by Mulvey (2015) who found that UK asylum policy actively inhibited refugee integration in the devolved Scottish context. Whilst there are similarities between Wales and Scotland, there are also differences that are worthy of consideration. Firstly, although the Scottish Government has greater devolved powers than the Welsh Government, in terms of refugee integration these are broadly similar and both have espoused a more inclusive and welcoming discourse to immigration than the UK government. However, Scotland has only one dispersal city (Glasgow) to which all asylum seekers dispersed to Scotland are sent, whereas there are four dispersal locations in Wales. Thus, in terms of place, refugees and asylum seekers are likely to be more geographically concentrated in Scotland than they are in Wales.

Whilst it is encouraging that many of the proposals in the Nation of Sanctuary Plan (2019) would directly address issues raised by participants in this research, particularly through the 'ReStart: Refugee Integration' project and increase in ESOL provision, it is clear that the Welsh Government approach is continuing to diverge from, and is fighting against, the UK government's asylum policy. The publication of the Nationality and Borders Bill in 2021 by the UK government, suggests that this policy divergence will continue for the foreseeable future, should the bill be enacted in Parliament. Indeed, the measures included in this Bill which seek to create a two-tier system based on how refugees arrive in the UK, criminalising those that don't arrive by authorised means, suggest that the UK government focus on deterrence rather than integration still persists. Whilst there appears to be no appetite from the Welsh Government for asylum policy to be devolved, the evidence presented in this article suggests that it is time for this to happen, so that the ambition of making Wales a true 'Nation of Sanctuary' can be realised. Such an approach would also allow all refugees and asylum seekers the chance to integrate from their first day of arrival in Wales as envisioned by the Welsh Government, without the restrictions of UK government asylum policies described here.

*Correspondence address: Dr Samuel Parker, Curzon Building, Birmingham City University, 4 Cardigan Street, Birmingham, B4 7BD. Tel: 01213315265. Email: Samuel.Parker@bcu.ac.uk

\section{References}

Ager, A. and Strang, A. (2004) Indicators of integration. London: Home Office.

Allsopp, J., Sigona, N. and Phillimore, J. (2014) Poverty among refugees and asylum seekers in the UK: An evidence and policy review. IRiS Working Papers Series.

Bloch, A. and Schuster, L. (2005) At the extremes of exclusion: Deportation, detention and dispersal. Ethnic and Racial Studies, 28, 3, 491-512.

Braun, V. and Clarke, V. (2006) Using thematic analysis in psychology. Qualitative research in psychology, 3, 2, 77-101.

Castles, S., De Haas, H. and Miller, M. J. (2014) The age of migration: International population movements in the modern world. $5^{\text {th }}$ ed. Basingstoke: Palgrave Macmillan.

Chaney, P. (2011) Equality and public policy exploring the impact of devolution in the UK. Cardiff: University of Wales Press.

Chick, M. and Hannagan-Lewis, I. (2019) Language Education for Forced Migrants: Governance and Approach. Languages, 4, 3, 1-19. 
p. 84. Inhibiting integration and strengthening inequality? The effects of UK policy making on refugees and asylum seekers in Wales

Cholewinski, R. (1998) Enforced destitution of asylum seekers in the United Kingdom: the denial of fundamental human rights. International Journal of Refugee Law, 10, 3, 462-498.

CLG (2012) Creating the conditions for integration. London: CLG.

Crawley, H. (2013) Asylum Seekers and Refugees in Wales. Cardiff: Wales Strategic Migration Partnership.

Crawley, H. (2014) Migration and Education in Wales. Cardiff: Wales Migration Partnership.

Crawley, H. and Crimes, T. (2009) Refugees living in Wales: a survey of skills, experiences and barriers to inclusion. Swansea: Swansea University.

Favell, A. (1998) Philosophies of integration: immigration and the idea of citizenship in France and Britain. Basingstoke: Macmillan/Centre for Research in Ethnic Relations.

Giudici, M. (2012) Immigrant narratives and nation-building in a stateless nation: the case of Italians in post-devolution Wales. Ethnic and Racial Studies, 37, 8, 14091426.

Goodfellow, M. (2019) Hostile Environment. London: Verso.

Gov.uk (2018) Asylum support. Available at: https://www.gov.uk/asylum-support/whatyoull-get [Accessed: 20/7/2018].

Home Office (2000) Full and Equal Citizens: A Strategy for the integration of refugees into the United Kingdom. London: Home Office.

Home Office (2005) Integration Matters: A National Strategy for Refugee Integration. London: Home Office.

Home Office (2021) Immigration Statistics, year ending December 2020. Available at: https://www.gov.uk/government/statistics/immigration-statistics-year-endingdecember-2020 [Accessed: 01/05/2021].

Mulvey, G. (2015) Refugee integration policy: the effects of UK policy-making on refugees in Scotland. Journal of Social Policy, 44, 2, 357-375.

Mulvey, G. (2017) Social Citizenship, Social Policy and Refugee Integration: a Case of Policy Divergence in Scotland? Journal of Social Policy, 1-18.

Phillimore, J. (2011) Monitoring for equality? Asylum seekers and refugees' retention and achievement in English for Speakers of Other Languages (ESOL). International Journal of Inclusive Education, 15, 3, 317-329.

Phillimore, J. (2012) Implementing integration in the UK: Lessons for integration theory, policy and practice. Policy \& Politics, 40, 4, 525-545.

Refugee Action (2013) Written Submission to Home Affairs Committee. Prepared 13 October 2013. Available At: http://www.publications.parliament.uk/pa/cm201314/cmselect/cmhaff/71/71v w32008 HC71 01 V IRT HomeAffairs ASY-18.htm [Accessed: 10/02/2019].

Robinson, V. (1999) Cultures of ignorance, disbelief and denial: refugees in Wales. Journal of Refugee Studies, 12, 1, 78-87.

Sales, R. (2002) The deserving and the undeserving? Refugees, asylum seekers and welfare in Britain. Critical social policy, 22, 3, 456-478.

Sales, R. (2007) Understanding immigration and refugee policy: contradictions and continuities. Bristol: Policy Press.

Stewart, E. and Mulvey, G. (2014) Seeking safety beyond refuge: the impact of immigration and citizenship policy upon refugees in the UK. Journal of Ethnic and Migration Studies, 40, 7, 1023-1039.

Welsh Government (2019) Nation of Sanctuary - Refugee and Asylum Seeker Plan. Cardiff: Welsh Government. 